\title{
Research on Learning Motivation and Autonomous L2 Learning
}

\author{
Zhang Ling \\ School of Foreign Languages and Cultures, Beijing Wuzi University, Beijing, 101149, China. \\ irene_zhangling@hotmail.com
}

\begin{abstract}
This paper is designed to analyze, in depth, the function of motivation in autonomous second language learning contexts. A questionnaire survey about motivation is conducted in 120 third-year students in Beijing Wuzi University in terms of internal motivation, external motivation, attribution and autonomous learning methods. The results showed that there is a high-correlation between learning motivation and autonomous learning outcomes.

Index Terms - L2 learning, autonomy, motivation
\end{abstract}

\section{Introduction}

Motivation is usually understood to refer to the desire to initiate L2 learning and the effort employed to sustain it. To some degree, motivation is a very important factor, which can help to determine the level of proficiency achieved by learners. Over three decades ago, Gardner (1972) framed a model of L2 learning known as the socio-educational model which would become the dominant model of L2 learning motivation. Gardner and Lambert (1972) defined 'motivation' in terms of the L2 learner's overall goal or orientation, and 'attitude' as the persistence shown by the learner in striving for a goal. This is a static model of L2 learning motivation, while Deci \& Ryan (1985) developed the self-determination theory which views motivation in a dynamic way.

Autonomy is capability of managing personal affairs, independent from the control of others. To become autonomous - in the terms of Broady \& Kenning(1996) - the learner also needs to develop learning management skills, which call for high internal motivation to achieve. In other words, learners are supposed to manage their own learning process, such as setting the learning goal, determine what to learn and how fast, and choose the appropriate learning techniques.

Although considerable work has been done within the field of learning motivation and autonomous learning, little research has been done to investigate how motivation interacts with autonomous learning in second language classrooms. And, there still remains a question in our mind: Is there certain correlation between learning motivation and autonomous learning? So the present paper attempts to apply some recent theories of linguistic and pedagogies and related research findings to expose the deep function and possible reasons for what we have not reached. This essay will first provide some of the basic segments and then analyze, in depth, the function of motivation in autonomous second language learning contexts.

\section{Literature review}

For Chinese L2 learners, it takes them almost 10 years to learn English. But they could hardly gain high language proficiency. The reason could be boiled down to low learning efficiency which calls for teachers and researchers to make an effort to solve. So, if learners know how to stimulate their interests in learning and motivate themselves to keep on learning, they will catch any target that they want.

\section{A. Researches on motivation}

It has been proved that motivation plays an important role in students' foreign language learning, and English learning in particular. The study of motivation has undergone a long time and has developed into a range of theories in which varieties of factors are involved. The term motivation is generally referred to certain force or inner power that gets people going, keeps people moving, and helps people get work done. It seems to be impossible for researchers to reach consensus on what motivation is.

According to Spolsky (2000), motivation is concerned with the question "Why does an organism behave as it does?" (p.149) Motivation involves four aspects: a goal, an effort, a desire to attain the goal, favorable attitude toward the activity in question. Guo (2005) defines that motivation is caused and stimulated by a certain goal and it will force the individual to act. While in the motivation research area, the socialeducational model has been in the dominant place for years and exerts great impacts on the motivation research. Based on the study of integrative motivation, the model developed by Gardner (1985) focuses on the L2 acquisition in bilingual language learning community. The model divides the motivation into integrative motivation and instrumental motivation, in which the former is considered as the major one. Based on their research, the students with integrative motivation are more active in class and take more participation, therefore, with more effective and efficient outcome. Some drawbacks can be concluded as the model has little connection with the language class teaching practices and fails to take all the congnitive factors into consideration, while the relations between motivation and learning autonomy are barely covered.

While Deci \& Ryan (1985) offered a more dynamic model as they developed the self-determination theory, which takes into consideration three aspects of motivation as amotivation, internal motivation and external motivation. Internal motivation refers to the self-satisfaction and sense of accomplishments while acquisition of L2 which is based on self-esteem ranks the first. 


\section{B. Researches on learning metacognition}

Cognition, as indicated above, means learning, metacognition means learning to learn. This implies that students can be taught and trained to be more effective learners. This is very important for the learners with low language learning efficiency and attainment. The research indicates that children with low L2 proficiency may be weak in metacognitive awareness and therefore have difficulty in knowing how to go about tackling a task. Without appropriate encouragement and motivation, this group of learners would easily give up learning, which will make the situation even worse. The relations between metacongnition and autonomous learning has long been a topic for linguistic and language practitioners. There are three types of strategies used by L2 students depending on the level or type of processing involved: metacoginitive, cognitive and social/affective strategies. Metacongnitive strategies include planning and thinking that involves active control over the thinking process which is used in learning situations. Planning the way to approach a learning task, monitoring comprehension and evaluating the progress towards the completion of a task are the skills that are metacognitive in their nature. Metacongnition helps learners define their cognition and at the same time concentrate on their learning plans, process and the evaluation by themselves and, therefore, enhance their communicative skills. The process is actually a typical independent learning process.

\section{Researches on learning autonomy}

Class hours are far from enough for grasping a foreign language which needs constant practice to make it perfect. It is well known by the L2 teachers that teaching learners how to learn, learner autonomy and learner independence have significantly influenced EFL language education. There are numerous definitions of autonomy and other synonyms for it in relevant literature, such as 'independence' (Sheerin, 1991), 'language awareness' (Vanlier, 1996). In the opinion of Pinkman (2005), learner autonomy and learner independence in language teaching are synonyms and used interchangeably. In the late 1970s, in the report Holec (1981) was commissioned to write for the Council of Europe, he defined autonomy as "the ability to take charge of one's learning" (p.3). He highlighted that learners have to work within a learning structure which enables them to exercise their ability to take control of their learning. According to him, to take charge of one's learning means to be responsible for all the decisions related to the learning process. Similar opinions were developed by Little $(1991$,$) as learner autonomy is a$ 'capacity for detaching critical reflection, decision making, and independent action" (p.4). Independent learners are better able to understand what is being taught, achieve learning objectives, monitor their own learning and use appropriate learning strategies. In light of these findings, 'independence' and 'autonomy' imply that students take a greater degree of control over the content and methods of learning than is usual in classroom language learning context to develop their integrated language skills.
But Little (1990) argued that "Autonomy is not a synonym for self-instruction..., autonomy is not limited to learning without a teacher"(p.70). He highlighted the importance of a counsellor in providing individual tutorials for guidance and encouragement in the process of moving from dependence to independence.

When it comes to the deeper connotation of "independent learning", Berge (1995) opened another door as he put emphasis on the notion of cooperating with others as a socially responsible person. This definition shows that he mainly focuses on the result of independence as cooperation while others may put more attention to the result of independence as being alone. So this defines 'independent learning' as social activity rather than individual.

However, as Tudor (1996) pointed out, the characteristics and strategies discussed cannot be simply 'pedagogised' and used to enable all learners to become successful. Independent learning is a process which happens to different learners in different ways.

\section{Research questions}

In this research, by analysing the learning motivations of learners, the attribution of their language studies and their autonomous learning methods, the relation between learning motivation and the autonomous learning will be examined. The following research questions will be addressed:

1). Are the learners highly-motivated?

2). What do learners attribute their success and failure of language learning to?

3 ). How to define the relation between learning motivation and the autonomous learning?

4). Is there certain correlation between learning motivation and autonomous learning?

\section{Research methodology}

This part introduces the research method involved in this study and explains how the method reaches reliable results, continues with the examination of the obtained data.

The questionnaire and analysis are used to answer the research questions.

Subjects: 120 the third-year university students

School: School of Foreign Languages and Cultures

Major: English

The questionnaire format:

The first part: the internal motivation

The second part: the external motivation

The third part: attribution of success or failure

The fourth part: autonomous learning methods

\section{Questionnaire results}

As table-1 indicates, the questionnaire students have strong internal motivation. Of all the questions, the fourth one "Needs for communication with foreigners" ranks the highest, and then follows "Interested in English movies and series". Based on this, it is easy to draw a conclusion that the students chose English as a major mainly based on interests. 
Table-1 Internal motivation

\begin{tabular}{|l|c|c|}
\hline questions & Mean & Std. Deviation \\
\hline Interested in the target culture & 4.09 & .714 \\
\hline Interested in English movies and series & 4.12 & .735 \\
\hline Interested in English & 4.02 & .587 \\
\hline Needs for communication with foreigners & 4.15 & .746 \\
\hline
\end{tabular}

As table-2 shows, the students are benefit-oriented in English learning, since they want certificates and therefore a better job. The items with high benefits associated rank high. They consider English as a useful tool for better social recognition.

Table-2 External motivation

\begin{tabular}{|l|c|c|}
\hline questions & Mean & Std. Deviation \\
\hline English is a useful tool & 4.87 & .714 \\
\hline For English proficiency certificates & 4.12 & .735 \\
\hline For a better job & 4.82 & .587 \\
\hline For high social status & 4.35 & .746 \\
\hline Pass exams & 3.98 & .883 \\
\hline
\end{tabular}

As table-3 shows, the highest mean is "Attribute success to hard work", and then the ability, while the lowest is the good or bad luck. From this we can tell that the students view hard work as a key to success of language learning.

Table-3 Attribution

\begin{tabular}{|l|c|c|}
\hline questions & Mean & Std. Deviation \\
\hline Attribute success to hard work & 4.87 & .714 \\
\hline Attribute success to ability & 3.76 & .735 \\
\hline Attribute success to good luck & 2.89 & .587 \\
\hline Attribute success to tasks & 3.01 & .746 \\
\hline Attribute failure to effortless work & 4.09 & .883 \\
\hline Attribute failure to inability & 3.87 & .759 \\
\hline Attribute failure to bad luck & 2.82 & .565 \\
\hline Attribute failure to hard tasks & 3.23 & .796 \\
\hline
\end{tabular}

Table-4 Autonomous learning methods

\begin{tabular}{|l|c|c|}
\hline questions & Mean & Std. Deviation \\
\hline Setting clear goals & 4.68 & .714 \\
\hline Making learning plans & 4.76 & .735 \\
\hline Making reasonable timetable & 3.89 & .687 \\
\hline Sufficient learning materials & 3.01 & .746 \\
\hline Suitable learning materials & 4.09 & .883 \\
\hline Original movies & 3.87 & .759 \\
\hline Communicating with native speakers & 4.52 & .765 \\
\hline Self-evaluation & 3.23 & .796 \\
\hline Extensive reading & 3.09 & .785 \\
\hline Build L2 learning confidence & 3.08 & .698 \\
\hline Self-regulation & 3.90 & .736 \\
\hline
\end{tabular}

From table-4, we can tell that the students view the methods, "Setting clear L2 learning goals" and "Making learning plans", as the most effective way to attain L2 skills. The students would like to put more efforts on setting goals and searching materials and try to find themselves a proper way to attain L2 skills. They rank "Suitable learning materials" higher than "Sufficient learning materials", which indicates a healthy learning manner as choosing suitable materials is more important than reading a lot of tough materials. The table also shows that the students are looking forward to a more native-like language environment to practice their English and consider this as a good way to gain a better language attainment. As the afterward interview to the questionnaire students indicates that most of them have relatively low recognition of their English proficiency level, but they all have strong desire to improve their English.

Four factors (internal motivation, external motivation, attribution and learning methods) are examined in the questionnaire, $90 \%$ of which are higher than 0.6 . The autonomous learning has correlation with the abovementioned factors, high positive correlation with 'internal motivation' while negative correlation with 'external motivation'. As the results suggest, there really exists the correlation between autonomous learning and motivation. Compared with the other factors, the internal motivation has the highest correlation, which indicates the stronger internal motivation is, the better autonomous learning will be.

\section{The discussion of findings}

Motivation plays a role as prerequisite for language learning and determines the efficiency and outcome of language learning. In order for learners to develop their independent learning skills to improve the learning efficiency, more efforts should be exerted on the following aspects:

\section{A. The cultivation of learners' confidence}

Self-belief is crucial if one accomplishes any degree of success and motivation. Yet the education system is often geared to select and grade. These factors can totally wipe out any element of self-belief. Even those who seem to have achieved a great deal of success in the class or in the playing field still need and rely on positive feedback to assure them of their own abilities. The key point here is that it is not taken for granted and assumed that some successful learners do not need positive and continuous feedback and encouragement in order to develop and maintain self-belief.

The encouragement for learners to express themselves, dig their potentials and develop their personality enables them to have a better performance in language application, therefore, enjoy their accomplishments. In the specific language tasks, teachers should assign suitable homework for learners, help them construct the appropriate steps and strategies and set the clear goals and finally offer them opportunities to display their outcomes. This is a good method to enhance learner's self-esteem and self-actualization.

\section{B. The encouragement of creativity}

It is interesting to reflect on the fact that many creative people can only take control of their own learning after they leave school. This is because the examination system often does not encourage creativity. There are certainly signs that progress is being made in this area but often the pace of learning is fast to ensure that all examinable areas of the curriculum are covered. This means that there is little scope 
for digressing and encouraging creativity. More open tasks need to be introduced to language learning process such as essay writing, where learners are allowed to have different opinions.

\section{The creation of autonomous friendly-learning atmosphere for learners}

This is involved in some basic requirements for language teachers as they are supposed to be more sincere and kind, which bears the consistency with the people-oriented principle of Chinese education. What teachers need to know is not only the language proficiency of the learners but also the personal needs and attitudes to build a harmonious teacher-student relation. Teachers should give them opportunities to make their plans, choose what they are interested in to fulfil the learning tasks in their own way. And curriculum and syllabus should be appropriately designed.

\section{The update of interest in learning}

The task is chosen to trigger the learners' internal motivation and enable them to take it as a good skillacquisition opportunity instead of a heavy burden. Different tasks are combined together with their learning interests to enhance their enthusiasm. On top of the required lessons, some supplementary learning materials could be added to attract learner's attention, especially the materials from aboard which can offer learners more international exposure. Besides, the combination of authentic and synthetic materials would enable learners to have more access to the real world where they will apply their language skills in.

\section{E. The guidance of reasonable attribution concept}

The major contribution of Attribute Theory to language learning is developed by Dornyei (1997) as re-attribution theory, according to which, the reasonable attribution directly effects the learning motivation. A teacher, as a guider of the learning process, should give students proper training about the attribution skills to foster them with a right and reasonable attribution and help them to realize the relations between success and hard work, and at the same time learn that they themselves take the dominant control over the whole learning process

\section{F. Well-found control and feedback}

The general evaluation methods can be divided into teacher evaluation, self-evaluation and interevaluation. In the evaluation process the value of learning tasks should be highlighted and the feedback should be instructed in a proper way to encourage more progress. The current situation of evaluation in Chinese universities is short of self-evaluation which contributes a lot to cultivating the concept for students that they take control over the learning process and therefore generate more internal motivation to strengthen their independent learning skills for a better learning outcome.

\section{G. The nurture of learners' integrativeness}

Gardner (2001) regards integrative motivation as the highest and most facilitative form of motivation and asserts that exceptionally successful learners who attain native-like competence are likely to be integratively motivated individuals. Encouraging learners to integrate themselves into a L2 environment to communicate with foreigners to improve their L2 competence and proficiency is essential to build the integrativeness. Though the L2 communication environment is not directly available to every L2 learners in China, it can still be achieved by using all kinds of on-line communication tools as MSN, Skype, by which they can enter into a L2 community by long-distance chatting with foreigners after class.

\section{Conclusion}

Based on the analysis of the data obtained from the questionnaire, the research indicates the correlation between learning motivation and autonomous learning, and gives some suggestions on how to cultivate high learning motivation to develop learners' autonomous learning skills for a better L2 attainment. The learners who participated in the survey are generally highly-motivated and have strong desire to attain English. However, they are bothered by the lack of good guidance and learning environment. Therefore, a good management of L2 teaching and curriculum design, and an integration of motivation-oriented cultivations need to be put on the top of the agenda.

Although the investigation in this research has covered some factors concerning learner' L2 motivation and autonomous learning, there must be many other variables that affect their learning motivation and attainment. The research only involves 120 subjects and one grade of students. Therefore, the result of the investigation may not be very convincing. The deeper effectiveness of learning motivation on autonomous L2 learning and attainment or the correlation between them needs a further research.

\section{References}

[1] Berge, Z. (1995). The role of the online instructor/facilitator. Educational Technology 35(1), 22-30.

[2] Broady, E. and Kenning, M. (1996), Promoting learner autonomy in university language teaching. London: Centre for Information on Language Teaching and Research.

[3] Deci, E., \& Ryan, R. (Eds.). (2002). Handbook of self-determination research. Rochester. NY: University of Rochester Press.

[4] Dornyei, Z, (1994) Motivation and motivating in the foreign language classroom. The Modern Language Journal, 78(3), 273-284.

[5] Gardner, R. and Lambert, W. (1972). Attitudes and motivation in secondlanguage learning. Rowley, Ma.: Newbury House.

[6] Gardener, R. C. (1985). Social psychology and second language learning: The role of attitudes and motivation. London: Edwqrd Arnorld.

[7] Guo, D. J. (2005), Theory and practice of psychological motivation .Beijing: Renmin Educational Press.

[8] Holec. H. (1981). Autonomy and foreign language learning. Oxford: Pergamon Press. Strabourg, Council of Europe.

[9] Little.D. (1991). Learner autonomy: definitions, issues and problems. Dublin: Authentik.

[10] Pinkman. K. (2005). Using blogs in the foreign language classroom: Encouraging learner independence. The JALT CALL Journal, 45(1), 2-24

[11] Sheerin, S. (1991). State of the art: self-access. Language Teaching, 24(3), 153-157.

[12] Spolsky, B.(2000). Conditions for second language learning. Shanghai: Shanghai Foreign Language Education Press.

[13] Tudor, I. (1996). Learner-centredness as language education. Cambridge: Cambridge University Press.

[14] Vanlier. L. (1996). Introducing language awareness.London: Penguin Books Ltd. 